\title{
Bifurkasi Hopf pada model prey-predator-super predator dengan fungsi respon yang berbeda
}

Dian Savitri and Hasan S. Panigoro

To cite this article:

D. Savitri and H. S. Panigoro, "Bifurkasi Hopf pada model prey-predator-super predator dengan fungsi respon yang berbeda", Jambura J. Biomath, vol. 1, no. 2, pp. 65-70, 2020

DOI: https://doi.org/10.34312/jjbm.v1i2.8399

(C) 2020 Author(s).

\section{Articles You may be interested in}

A stage-structure Rosenzweig-MacArthur model with effect of prey refuge

L. K. Beay and M. Saija

http://dx.doi.org/10.34312/jjbm.v1i1.6891

Analisis kestabilan model predator-prey dengan infeksi penyakit pada prey dan pemanenan proporsional pada predator

S. Maisaroh, Resmawan, and E. Rahmi

http://dx.doi.org/10.34312/jjbm.v1i1.5948

Bifurkasi Hopf pada model Lotka-Volterra orde-fraksional dengan Efek Allee aditif pada predator

H. S. Panigoro and D. Savitri

http://dx.doi.org/10.34312/jjbm.v1i1.6908

Discrete-time prey-predator model with $\theta$-logistic growth for prey incorporating square root functional response

P. K. Santra

http://dx.doi.org/10.34312//jjbm.v1i2.7660

Global stability of a fractional-order logistic growth model with infectious disease

H. S. Panigoro and E. Rahmi

https://doi.org/10.34312/jjbm.v1i2.8135 


\title{
Bifurkasi Hopf pada model prey-predator-super predator dengan fungsi respon yang berbeda
}

\author{
Dian Savitri ${ }^{1,3, *}$, Hasan Panigoro ${ }^{2,3}$ \\ ${ }^{1}$ Jurusan Matematika, Universitas Negeri Surabaya, Surabaya 60292, Indonesia \\ ${ }^{2} J u r u s a n$ Matematika, Universitas Negeri Gorontalo, Bone Bolango 96119, Indonesia \\ ${ }^{3}$ Jurusan Matematika, Universitas Brawijaya, Malang 65145, Indonesia \\ *Penulis Korespondensi. Email: diansavitri@unesa.ac.id
}

\begin{abstract}
Abstrak
Artikel ini membahas model satu-prey, satu-predator, dan super predator dengan laju pemangsaan predator terhadap prey menggunakan fungsi respon Holling tipe I dan laju pemangsaan super predator terhadap predator menggunakan fungsi respon Holling tipe II. Dari hasil analisis diperoleh satu titik kritis kepunahan semua populasi yang selalu tidak stabil dan dua titik kritis lainnya, yaitu titik kepunahan super-predator dan titik eksistensi semua populasi yang masing-masing stabil bersyarat. Selanjutnya diberikan simulasi numerik berupa diagram bifurkasi dan potret fase dari solusi model. Diagram bifurkasi diperoleh dengan memvariasikan parameter konversi pertumbuhan predator menjadi super predator yang menghasilkan bifurkasi maju dan Hopf. Bifurkasi maju terjadi di sekitar titik kepunahan super-predator, sedangkan bifurkasi Hopf terjadi di sekitar titik interior model. Berdasarkan syarat eksistensi dan simulasi numerik ditunjukkan bahwa parameter tingkat konversi pertumbuhan spesies predator menjadi super predator mengendalikan dinamika sistem dan eksistensi dari predator.
\end{abstract}

Kata Kunci: Bifurkasi Hopf; Bifurkasi maju; Holling tipe I dan II; Kontinuasi Numerik

\begin{abstract}
This article discusses the one-prey, one-predator, and the super predator model with different types of functional response. The rate of prey consumption by the predator follows Holling type I functional response and the rate of predator consumption by the super predator follows Holling type II functional response. We identify the existence and stability of critical points and obtain that the extinction of all population points is always unstable, and the other two are conditionally stable i.e., the super predator extinction point and the co-existence point. Furthermore, we give the numerical simulations to describe the bifurcation diagram and phase portraits of the model. The bifurcation diagram is obtained by varying the parameter of the conversion rate of predator biomass into a new super-predator which gives forward and Hopf bifurcation. The forward bifurcation occurs around the super predator extinction point while Hopf bifurcation occurs around the interior of the model. Based on the terms of existence and numerical simulation, we confirm that the conversion rate of predator biomass into a new super-predator controls the dynamics of the system and maintains the existence of predator.
\end{abstract}

Keywords: Hopf Bifurcation; Forward Bifurcation; Holling type I and II; Numerical Continuation

\section{Pendahuluan}

Pemodelan matematika tentang masalah ekologi berkembang pesat setelah Lotka (1925) dan Volterra (1931) mengajukan model predator-prey yang dikenal sebagai model Lotka-Volterra. Model ekologi klasik ini menjadi cikal bakal diajukannya model predator-prey lain, seperti model Rosenzweig-MacArthur [1-3] dan model Leslie-Gower [4-14] yang berfokus pada sistem dengan dua spesies, yaitu satu prey dan satu predator. Lebih lanjut, agar dapat memberikan pemahaman yang lebih baik terhadap dinamika sistem ekologi yang kompleks maka kajian tentang model tiga spesies dipandang menarik untuk dilakukan. Sarwardi dkk. [15] mengkaji model satu-prey dua-predator mengikuti model Lotka-Volterra dengan mengasumsikan spesies prey dimangsa kedua spesies predator dengan menggunakan fungsi respon Holling tipe II serta adanya kompetisi antara kedua spesies predator. Kajian yang serupa dilakukan oleh Savitri dkk. [16] yang membahas model satu-prey dua-predator dengan mempertimbangkan model Leslie-Gower pada pertumbuhan kedua spesies predator. Kedua predator yaitu predator-1 dan predator-2 diasumsikan tidak saling memangsa dan ada kompetisi antar kedua predator tersebut dalam memperebutkan mangsa dengan fungsi respon terhadap prey yang digunakan adalah fungsi respon Holling tipe I.

Berdasarkan model satu-prey dua-predator, dapat dikembangkan model prey-predator-super predator seperti yang dilakukan oleh Reddy dkk. [17] yang mengasumsikan bahwa laju pemangsaan super predator terhadap predator dan predator terhadap prey masing-masing mengikuti fungsi respon Holling tipe I. Pada model tersebut 
diasumsikan terjadi kompetisi pada spesies prey, predator, dan super predator. Kajian yang serupa dilakukan oleh Savitri dan Abadi [18] dengan mengasumsikan bahwa laju pemangsaan predator pertama terhadap prey dan predator kedua terhadap predator pertama masing-masing mengikuti fungsi respon Holling tipe II dan kompetisi hanya terjadi pada spesies prey.

\section{Formulasi Model}

Terinspirasi dari peneliti terdahulu, maka pada artikel ini dikonstruksi model satu-prey, satu-predator, dan super predator dengan diasumsikan bahwa laju pertumbuhan spesies predator dibatasi oleh kepadatan populasi prey $x(t)$. Laju pemangsaan predator untuk prey menggunakan fungsi respon Holling tipe I dan laju pemangsaan super predator untuk predator menggunakan fungsi respon Holling tipe II. Asumsi tersebut disesuaikan dengan fenomena nyata dan karakteristik masing-masing spesies, untuk super predator membutuhkan waktu dalam menangani mangsa, meliputi: mencari, mencerna dan menghabiskan mangsa. Misalnya ikan-ikan kecil yang memakan krill dan udang yang bersesuaian dengan fungsi respon Holling tipe-I, dan ikan-ikan besar yang memangkan ikan-ikan kecil mengikuti Holling tipe-II. Model satu-prey, satu-predator, dan super predator, dengan kepadatan spesies prey yaitu $x(t)$, kepadatan spesies predator dinyatakan $y(t)$, dan kepadatan spesies super predator yaitu $z(t)$, sebagai berikut.

$$
\begin{aligned}
& \frac{d x}{d t}=r x\left(1-\frac{x}{K}\right)-\alpha x y, \\
& \frac{d y}{d t}=s y\left(1-\frac{y}{x}\right)-\frac{\beta y z}{1+m y}, \\
& \frac{d z}{d t}=\frac{\rho y z}{1+m y}-\mu z .
\end{aligned}
$$

Parameter pada model (1), yaitu $r, s, K, \alpha, \beta, m, \rho$, dan $\mu$ masing-masing merepresentasikan laju pertumbuhan prey, laju pertumbuhan predator, kapasitas daya tampung spesies prey, laju pemangsaan predator terhadap prey, laju pemangsaan super predator terhadap predator, waktu yang dibutuhkan super predator untuk menangani predator, tingkat konversi pertumbuhan predator menjadi super predator, dan laju kematian alami spesies super predator. Model (1) diberikan syarat kondisi awal $x(0)>0, y(0)>0$, dan $z(0)>0$, dimana semua parameter bernilai positif.

\section{Titik Kritis dan Kestabilannya}

Titik kritis model (1) diperoleh dengan menyelesaikan sistem persamaan berikut.

$$
\begin{aligned}
{\left[r\left(1-\frac{x}{K}\right)-\alpha y\right] x } & =0, \\
{\left[s\left(1-\frac{y}{x}\right)-\frac{\beta z}{1+m y}\right] y } & =0, \\
{\left[\frac{\rho y}{1+m y}-\mu\right] z } & =0,
\end{aligned}
$$

sehingga memberikan

1. Titik $E_{1}=(K, 0,0)$ yang menyatakan kepunahan predator dan super predator.

2. Titik $E_{2}=\left(\frac{r K}{K \alpha+r}, \frac{r K}{K \alpha+r}, 0\right)$ yang menyatakan kepunahan super predator.

3. Titik eksistensi dari semua populasi $E_{3}=\left(x^{*}, y^{*}, z^{*}\right)$ dengan

$$
\begin{aligned}
x^{*} & =\frac{\left(r-\alpha y^{*}\right) K}{r}, \\
y^{*} & =\frac{\mu}{\rho-\mu m^{\prime}}, \\
z^{*} & =\left(1-\frac{r y^{*}}{\left(r-\alpha y^{*}\right) K}\right) \frac{\left(1+m y^{*}\right) s}{\beta} .
\end{aligned}
$$

Titik kritis $E_{1}$ dan $E_{2}$ merupakan titik titik yang selalu terdefinisi secara biologis $\left(E_{1,2} \in \mathbb{R}_{+}^{2}\right)$, sedangkan titik kritis $E_{3} \in \mathbb{R}_{+}^{2}$ jika $\rho>\mu m+\frac{(K \alpha+r) \mu}{r K}$. Selanjutnya, perilaku solusi disekitar titik-titik kritis tersebut diberikan oleh beberapa teorema berikut. 
Teorema 1. Titik kritis kepunahan populasi kedua predator $E_{1}=(1,0,0)$ adalah titik pelana.

bukti. Matriks Jacobi dari titik kritis $E_{1}$ adalah

$$
J\left(E_{1}\right)=\left[\begin{array}{ccc}
-r & -K \alpha & -0 \\
0 & s & 0 \\
0 & 0 & -\mu
\end{array}\right]
$$

sehingga diperoleh nilai eigen $\lambda_{1}=-r<0, \lambda_{2}=s>0$ dan $\lambda_{3}=-\mu<0$. Dengan demikian $E_{1}=(K, 0,0)$ adalah titik pelana.

Teorema 2. Titik kepunahan populasi super predator $E_{2}=\left(\frac{r K}{K \alpha+r}, \frac{r K}{K \alpha+r}, 0\right)$ stabil asimtotik lokal jika $\rho<\mu m+$ $\frac{(K \alpha+r) \mu}{r K}$

bukti. Matriks Jacobi dari titik kritis $E_{2}$ adalah

$$
J\left(E_{2}\right)=\left[\begin{array}{ccc}
-\frac{r^{2}}{K \alpha+r} & -\frac{\alpha r K}{K \alpha+r} & 0 \\
s & -s & -\frac{\beta r K}{m r K+K \alpha+r} \\
0 & 0 & \frac{\rho r K}{m r K+K \alpha+r}-\mu
\end{array}\right] .
$$

sehingga diperoleh persamaan karakteristik

$$
\left(\frac{\rho r K}{m r K+K \alpha+r}-\mu-\lambda\right)\left(\lambda^{2}+\left(\frac{r^{2}}{K \alpha+r}+s\right) \lambda+r s\right)=0
$$

Dengan demikian diperoleh nilai eigen

$$
\begin{aligned}
\lambda_{1} & =\frac{\rho r K}{m r K+K \alpha+r}-\mu \\
\lambda_{2,3} & =-\frac{1}{2}\left(\frac{r^{2}}{K \alpha+r}+s\right) \pm \frac{1}{2} \sqrt{\left(\frac{r^{2}}{K \alpha+r}+s\right)^{2}-4 r s}
\end{aligned}
$$

Jelas bahwa $\lambda_{1}<0$ jika $\rho<\mu m+\frac{(K \alpha+r) \mu}{r K}$. Selanjutnya karena $\frac{r^{2}}{K \alpha+r}+s>0, r s>0$, dan $\left(\frac{r^{2}}{K \alpha+r}+s\right) r s>$ 0, maka $\operatorname{Re}\left(\lambda_{2,3}\right)<0$ baik untuk $\left(\frac{r^{2}}{K \alpha+r}+s\right)^{2}<4 r s$ ataupun $\left(\frac{r^{2}}{K \alpha+r}+s\right)^{2} \geq 4 r s$. Dengan demikian, $E_{2}$ stabil asimtotik lokal.

Teorema 3. Titik kritis interior ketiga populasi tumbuh bersama yaitu $E_{3}=\left(x^{*}, y^{*}, z^{*}\right)$ stabil asimtotik lokal jika $\rho>$ $\frac{\mu}{y^{*}} \sqrt{\frac{\beta m x^{*} z^{*}}{r}}$

bukti. Matriks Jacobi hasil linearisasi di sekitar titik kritis $E_{3}=\left(x^{*}, y^{*}, z^{*}\right)$ adalah

$$
J\left(E_{3}\right)=\left[\begin{array}{ccc}
-\frac{r x^{*}}{K} & -\alpha x^{*} & 0 \\
s\left(\frac{y^{*}}{x^{*}}\right)^{2} & \frac{\beta \mu^{2} m z^{*}}{\rho^{2} y^{*}}-\frac{r y^{*}}{x^{*}} & -\frac{\beta \mu z^{*}}{\rho} \\
0 & \frac{(\rho-\mu m) \mu z^{*}}{\rho y^{*}} & 0
\end{array}\right],
$$

yang memberikan persamaan karakteristik

$$
\left(\frac{r x^{*}}{K}+\lambda\right)\left[\lambda^{2}+\left(\frac{r y^{*}}{x^{*}}-\frac{\beta \mu^{2} m z^{*}}{\rho^{2} y^{*}}\right) \lambda+\frac{(\rho-\mu m) \beta \mu^{2}\left(z^{*}\right)^{2}}{\rho^{2} y^{*}}\right]=0 .
$$




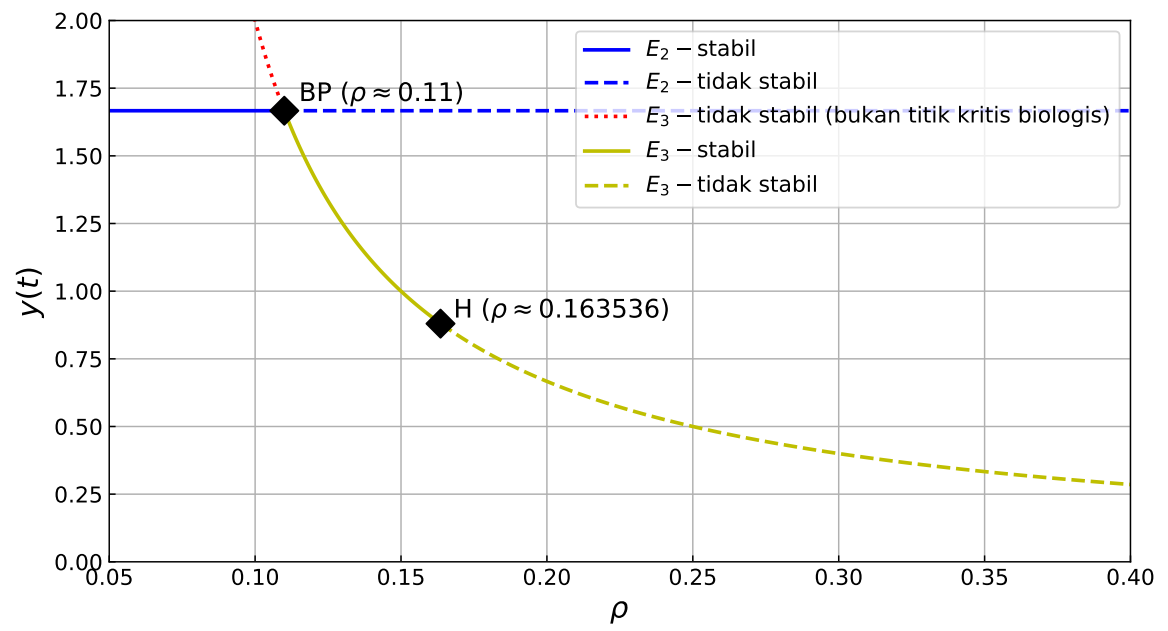

Gambar 1. Diagram Bifurkasi model (1). Terjadi bifurkasi maju dengan titik bifurkasi $\rho \approx 0.11$ dan bifurkasi Hopf dengan titik bifurkasi $\rho=0.163536$.

Dengan demikian, diperoleh nilai eigen:

$$
\begin{aligned}
\lambda_{1} & =-\frac{r x^{*}}{K} \\
\lambda_{2,3} & =\left(\frac{\beta \mu^{2} m z^{*}}{2 \rho^{2} y^{*}}-\frac{r y^{*}}{2 x^{*}}\right) \pm \sqrt{\left(\frac{\beta \mu^{2} m z^{*}}{2 \rho^{2} y^{*}}-\frac{r y^{*}}{2 x^{*}}\right)^{2}-\frac{(\rho-\mu m) \beta \mu^{2}\left(z^{*}\right)^{2}}{\rho^{2} y^{*}}}
\end{aligned}
$$

Jelas bahwa $\lambda_{1}<0$. Perhatikan pula bahwa dari syarat eksistensi $E_{3}$ diperoleh $\rho>\mu m$ sehingga $\frac{(\rho-\mu m) \beta \mu^{2}\left(z^{*}\right)^{2}}{\rho^{2} y^{*}}>0$. Karena $\rho>\frac{\mu}{y^{*}} \sqrt{\frac{\beta m x^{*} z^{*}}{r}}$ maka $\frac{r y^{*}}{x^{*}}-\frac{\beta \mu^{2} m z^{*}}{\rho^{2} y^{*}}>0$, sehingga $\operatorname{Re}\left(\lambda_{2,3}\right)<0$. Dengan demikian $\operatorname{Re}\left(\lambda_{1,2,3}\right)<0$ sehingga $E_{3}$ stabil asimtotik lokal.

Tabel 1. Syarat eksistensi dan kestabilan lokal titik kritis model (1)

\begin{tabular}{lcc}
\hline Titik kritis & Syarat eksistensi & Syarat kestabilan lokal \\
\hline$E_{1}=(K, 0,0)$ & - & titik pelana \\
$E_{2}=\left(\frac{r K}{K \alpha+r}, \frac{r K}{K \alpha+r}, 0\right)$ & - & $\rho<\mu m+\frac{(K \alpha+r) \mu}{r K}$ \\
$E_{3}=\left(x^{*}, y^{*}, z^{*}\right)$ & $\rho>\mu m+\frac{(K \alpha+r) \mu}{r K}$ & $\rho>\frac{\mu}{y^{*}} \sqrt{\frac{\beta m x^{*} z^{*}}{r}}$ \\
\hline
\end{tabular}

Keseluruhan analisis eksistensi dan kestabilan titik kritis diberikan pada Tabel 1. Berdasarkan hasil analisis yang diperoleh, eksistensi dan kestabilan titik kritis sangat dipengaruhi oleh tingkat konversi pertumbuhan predator menjadi super predator $(\rho)$. Dengan mengubah nilai $\rho$, maka akan terjadi perubahan eksistensi dan kestabilan dari $E_{2}$ dan $E_{3}$. Lebih khusus lagi, perubahan nilai $\rho$ dapat mengakibatkan perubahan kestabilan dari $E_{2}$ disertai munculnya titik kritis $E_{3}$ yang disebut dengan bifurkasi maju. Selain itu, dengan mengubah $\rho, E_{3}$ kehilangan kestabilannya dengan kondisi matriks Jacobi dititik tersebut bernilai kompleks, lihat bukti dari Teorema 3. Kondisi ini juga mengindikasikan terjadinya bifurkasi yang disebut dengan bifurkasi Hopf. Pada artikel ini, kedua bifurkasi tidak ditunjukkan secara analitik, namun akan diperlihatkan secara numerik pada pokok bahasan selanjutnya.

\section{Simulasi Numerik}

Simulasi numerik ini bertujuan untuk menggambarkan perilaku solusi model (1) disekitar titik-titik kritis berdasarkan nilai-nilai parameter yang disesuaikan dengan hasil teoritis yang diberikan pada Tabel 1 . Keseluruhan simulasi menggunakan nilai-nilai parameter sebagai berikut.

$$
r=0.6, s=0.4, K=10, \alpha=0.3, \quad \beta=0.3, \quad m=0.5 \text { dan } \mu=0.1 .
$$




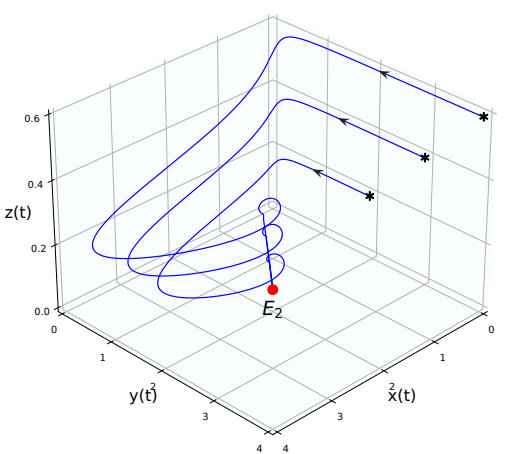

(a) $\rho=0.1$

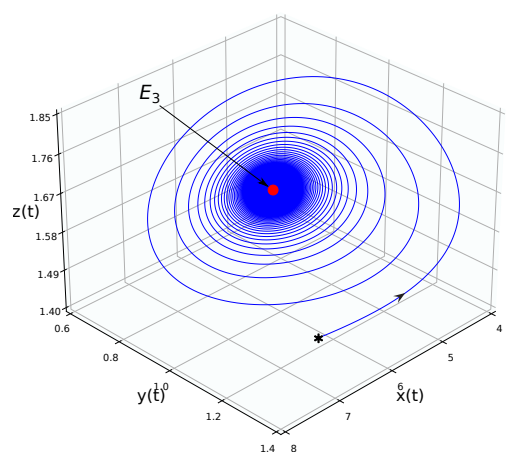

(b) $\rho=0.163$

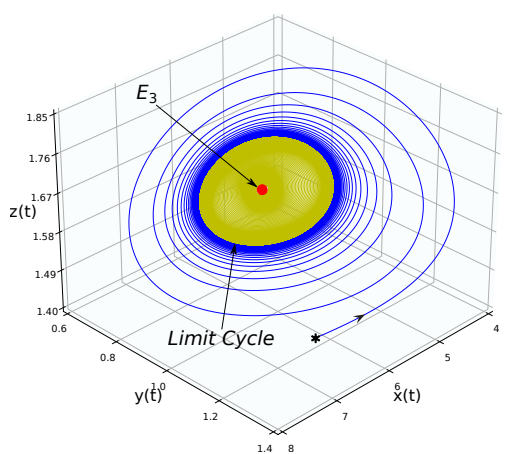

(c) $\rho=0.165$

Gambar 2. Potret Fase solusi model (1) disekitar titik kritis $E_{2}$ dan $E_{3}$

Simulasi numerik dilakukan menggunakan integral Runge-kutta orde-4 yang ditampilkan melalui potret fase dengan software Python 3.8 .

Untuk melihat perilaku solusi secara menyeluruh, diidentifikasi kestabilan lokal dari titik kritis $E_{2}$ dan $E_{3}$ dengan menggerakan nilai parameter $\rho$ pada interval $0.05 \leq \rho \leq 0.4$. Diperoleh diagram bifurkasi seperti pada gambar Gambar 1. Titik kritis $E_{2}$ stabil asimtotik lokal pada saat $\rho \lesssim 0.11$ dan kehilangan kestabilannya ketika $\rho \gtrsim$ 0.11 . Kondisi ini juga disertai perubahan kestabilan $E_{3}$ ketika $\rho$ melewati 0.11 . Secara numerik, kondisi ini merupakan indikasi terjadinya bifurkasi Transkiritikal yang disimbolkan (BP) pada Gambar 1. Meski demikian, titik setimbangan $E_{3}$ sebelum $\rho \approx 0.11$ tidak terdefinisi secara biologis karena bernilai negatif. Oleh karena itu, secara biologis yang terjadi adalah fenomena bifurkasi maju dimana salah satu titik kritis di axial yang stabil berubah menjadi tidak stabil disertai dengan munculnya titik kritis stabil di interior dari model. Kestabilan dari $E_{2}$ diperlihatkan oleh potret fase pada Gambar 2(a) yaitu pada saat $\rho=0.1$. Solusi disekitar $E_{2}$ akan konvergen ke $E_{2}$ yang berarti bahwa terjadi kepunahan super predator.

Hal yang menarik lainnya terjadi disekitar titik interior dari model (1). Pada saat $\rho$ melewati 0.163536 , titik kritis $E_{3}$ kehilangan kestabilannya via bifurkasi Hopf. Untuk menggambarkan dinamika $E_{3}$ sebelum melewati titik bifurkasi Hopf $\rho \approx 0.163536$, dipilih $\rho=0.163$ sehingga diperoleh Gambar 2(b). Titik kritis $E_{3}$ stabil asimtotik lokal tipe spiral yang menyatakan semua solusi konvergen ke titik titik interior sehingga seluruh populasi akan terjaga eksistensinya. Pada saat $\rho \gtrsim 0.163536$, titik kesetimbangan $E_{3}$ kehilangan kestabilan via bifurkasi Hopf. Dengan menetapkan $\rho=0.165$, diberikan potret fase pada Gambar 2(c). Seluruh solusi akan konvergen ke suatu limit-cycle. Secara biologis, meskipun $E_{3}$ tidak stabil, eksistensi dari ketiga populasi akan tetap terjaga dengan kepadatan populasi ketiganya berubah secara periodik untuk $t \rightarrow \infty$.

\section{Kesimpulan}

Berdasarkan syarat eksistensi dan simulasi numerik menunjukkan bahwa parameter tingkat konversi pertumbuhan spesies predator menjadi super predator mengendalikan dinamika solusi model dan menjaga spesies predator tidak punah. Titik kritis $E_{2}$ dan $E_{3}$ stabil asimtotik dengan syarat. Hasil kontinuasi numerik pada model prey-predator-super predator diperoleh pengaruh adanya tingkat konversi pertumbuhan spesies predator menjadi tingkat pertumbuhan super predator mendorong munculnya perubahan kestabilan yang mengindikasikan fenomena terjadinya bifurkasi Hopf dan bifurkasi maju.

\section{Referensi}

[1] M. L. Rosenzweig dan R. H. MacArthur, "Graphical representation and stability conditions of predator-prey interactions," The American Naturalist, vol. 97, no. 895, hal. 209-223, 1963.

[2] M. Moustafa, M. H. Mohd, A. I. Ismail, dan F. A. Abdullah, "Stage structure and refuge effects in the dynamical analysis of a fractional order Rosenzweig-MacArthur prey-predator model," Progress in Fractional Differentiation and Applications, vol. 5, no. 1, hal. 49-64, 2019.

[3] L. K. Beay dan M. Saija, "A stage-structure Rosenzweig-MacArthur model with effect of prey refuge," Jambura Journal of Biomathematics (JJBM), vol. 1, no. 1, hal. 1-7, 2020.

[4] R. Mokodompit, N. Nurwan, dan E. Rahmi, "Bifurkasi periode ganda dan Neimark-Sacker pada model diskret Leslie-Gower dengan fungsi respon ratio-dependent," Limits: Journal of Mathematics and Its Applications, vol. 17, no. 1, hal. 19, 2020. 
[5] Y. Lin, X. Xie, F. Chen, dan T. Li, “Convergences of a stage-structured predator-prey model with modified Leslie-Gower and Holling-type II schemes," Advances in Difference Equations, vol. 2016, no. 1, 2016.

[6] Y. Cai, C. Zhao, W. Wang, dan J. Wang, "Dynamics of a Leslie-Gower predator-prey model with additive Allee effect," Applied Mathematical Modelling, vol. 39, no. 7, hal. 2092-2106, 2015.

[7] H. Ulfa, A. Suryanto, dan I. Darti, "Dynamics of Leslie-Gower predator-prey model with additional food for predators," International Journal of Pure and Aplied Mathematics, vol. 115, no. 2, hal. 751-765, 2017.

[8] H. S. Panigoro dan E. Rahmi, "Modifikasi sistem predator-prey: dinamika model Leslie-Gower dengan daya dukung yang tumbuh logistik," SEMIRATA MIPAnet, hal. 94-103, 2017.

[9] A. Suryanto dan I. Darti, "Dynamics of Leslie-Gower pest-predator model with disease in pest including pest-harvesting and optimal implementation of pesticide," International Journal of Mathematics and Mathematical Sciences, vol. 2019, article id 5079171, hal. 1-9, 2019.

[10] U. Salamah, A. Suryanto, dan W. M. Kusumawinahyu, "Leslie-Gower predator-prey model with stage-structure, Beddington-DeAngelis functional response, and anti-predator behavior," AIP Conference Proceedings, vol. 2084, no. 1, hal. 20001, 2019.

[11] H. S. Panigoro, E. Rahmi, N. Achmad, dan S. L. Mahmud, "The Influence of additive Allee effect and periodic harvesting to the dynamics of Leslie-Gower predator-prey model," Jambura Journal of Mathematics, vol. 2, no. 2, hal. 87-96, 2020.

[12] H. S. Panigoro, "Analisis dinamik sistem predator-prey model Leslie-Gower dengan pemanenan secara konstan terhadap predator," Euler, vol. 2, no. 1, hal. 1-12, 2014.

[13] S. Mondal, N. Bairagi, dan G. M. 'Guerekata, “Global stability of a Leslie-Gower-type fractional order tritrophic food chain model," Fractional Differential Calculus, vol. 9, no. 1, hal. 149-161, 2019.

[14] S. Pal, N. Pal, S. Samanta, dan J. Chattopadhyay, "Fear effect in prey and hunting cooperation among predators in a Leslie-Gower model," Mathematical Biosciences and Engineering, vol. 16, no. 5, hal. 5146-5179, 2019.

[15] S. Sarwardi, P. K. Mandal, dan S. Ray, "Dynamical behaviour of a two-predator model with prey refuge," Journal of Biological Physics, vol. 39, no. 4, hal. 701-722, 2013.

[16] D. Savitri, A. Suryanto, W. M. Kusumawinahyu, dan Abadi, "A dynamics behaviour of two Predators and one prey interaction with competition between predators," IOP Conference Series: Materials Science and Engineering, vol. 546, no. 5, hal. 052069, 2019.

[17] K. Shiva Reddy, K. Laksmi Narayan, dan N. Pattabhi Ramacharyulu, “A three species ecosystem consisting of a prey, predator and super predator," Mathematics Applied in Science and Technology, vol. 2, no. 1, hal. 95-107, 2010.

[18] D. Savitri dan Abadi, "Stability analysis and numerical simulation of 1 prey -2 predator system," AIP Conference Proceedings, vol. 1651, no. 1, hal. 114-117, 2015.

2020 by the Authors. This article is an open access article distributed under the terms and conditions of the Creative Commons Attribution-NonComercial 4.0 International License. Editorial of JJBM: Department of Mathematics, State University of Gorontalo, Jln. Prof. Dr. Ing. B. J. Habibie, Bone Bolango 96119, Indonesia. 


\section{Submit your manuscript at http://ejurnal.ung.ac.id/}

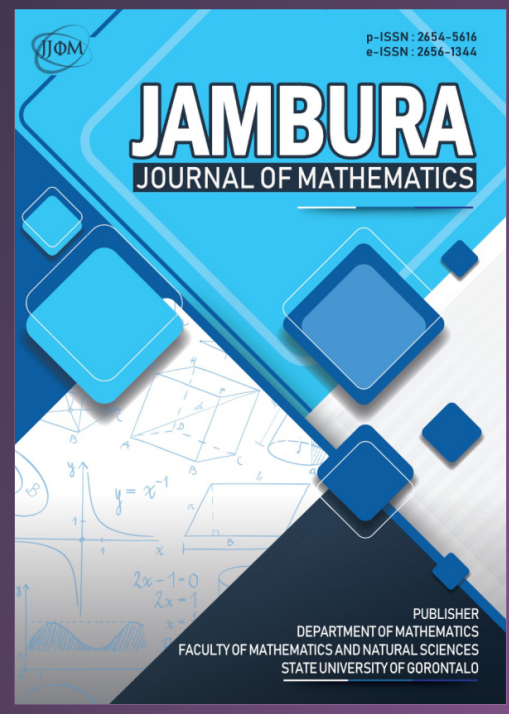

Jambura Journal of Mathematics

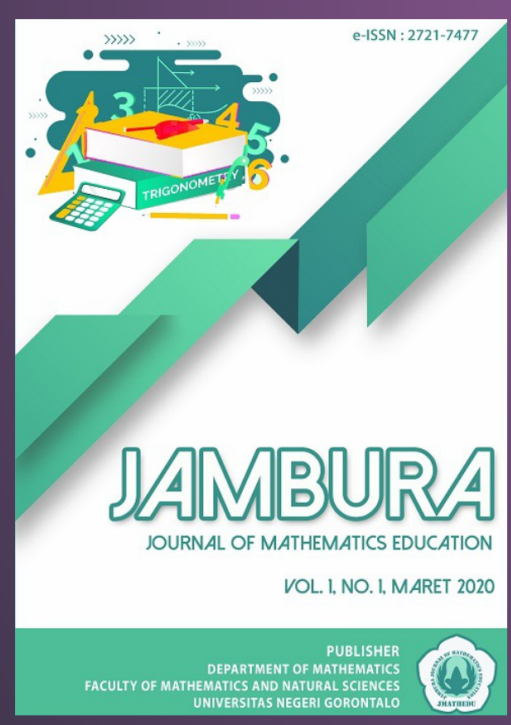

Jambura Journal of Mathematics Education
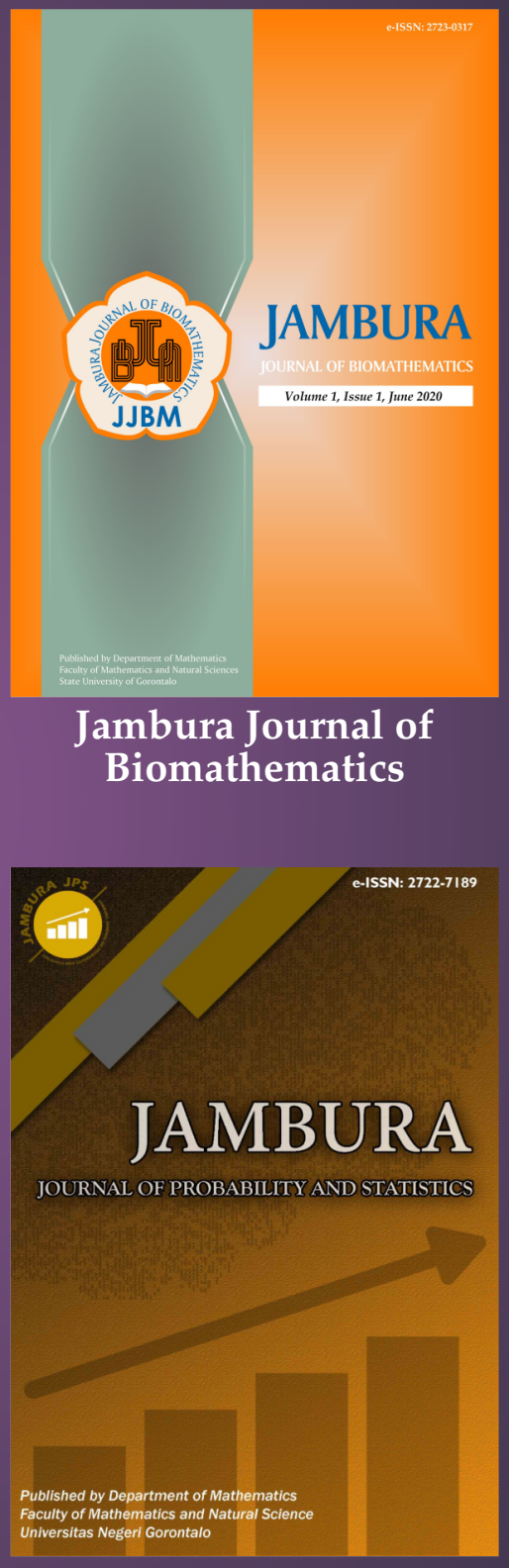

Jambura Journal of Probability and Statistics

Published by

Department of Mathematics

Faculty of Mathematics and Natural Sciences

State University of Gorontalo 